\title{
GLUTAMICS—a randomized clinical trial on glutamate infusion in 861 patients undergoing surgery for acute coronary syndrome
}

\author{
Mårten Vidlund, $\mathrm{MD}, \mathrm{PhD},{ }^{\mathrm{a}}$ Erik Håkanson, $\mathrm{MD}, \mathrm{PhD},{ }^{\mathrm{b}}$ Örjan Friberg, $\mathrm{MD}, \mathrm{PhD},{ }^{\mathrm{a}}$ \\ Sören Juhl-Andersen, MD ${ }^{\mathrm{c} \dagger}$ Jonas Holm, MD ${ }^{\mathrm{b}}$ Farkas Vanky, MD, PhD, ${ }^{\mathrm{b}}$ Lena Sunnermalm, MD, ${ }^{\mathrm{a}}$ \\ Jan-Olov Borg, $\mathrm{MD},{ }^{\mathrm{c}}$ Rajiv Sharma, $\mathrm{MD},{ }^{\mathrm{c}}$ and Rolf Svedjeholm, $\mathrm{MD}, \mathrm{PhD}^{\mathrm{b}}$
}

\begin{abstract}
Objective: Glutamate has been claimed to protect the heart from ischemia and to facilitate metabolic and hemodynamic recovery after ischemia. The GLUTAmate for Metabolic Intervention in Coronary Surgery trial investigated whether an intravenous glutamate infusion given in association with surgery for acute coronary syndrome could reduce mortality and prevent or mitigate myocardial injury and postoperative heart failure.
\end{abstract}

\begin{abstract}
Methods: In the present prospective, triple-center, double-blind study, 861 patients undergoing surgery for acute coronary syndrome were randomly assigned to an intravenous infusion of glutamate $(n=428)$ or saline $(\mathrm{n}=433)$ perioperatively.
\end{abstract}

\begin{abstract}
Results: The incidence of the primary endpoint - a composite of 30-day mortality, perioperative myocardial infarction, and left ventricular heart failure at weaning from cardiopulmonary bypass-was $7.3 \%$ versus $5.8 \%$ $(P=.41)$ in the glutamate and control groups, respectively. Patients with left ventricular failure at weaning from cardiopulmonary bypass had a shorter median intensive care unit stay ( $25 \mathrm{vs} 92$ hours; $P=.02$ ) if they were treated with glutamate. In patients with unstable angina (Canadian Cardiovascular Society class IV) undergoing isolated coronary artery bypass grafting $(\mathrm{n}=458)$, the incidence of severe circulatory failure according to the prespecified criteria was significantly lower in the glutamate group $(1.3 \% \mathrm{vs} 6.9 \% ; P=.004)$. On multivariate analysis, glutamate infusion was associated with a reduced risk of developing severe circulatory failure (odds ratio, $0.17 ; 95 \%$ confidence interval, $0.04-0.72 ; P=.02$ ). A relative risk reduction exceeding $50 \%$ for developing severe circulatory failure was seen in most risk groups undergoing isolated coronary artery bypass grafting, with those with diabetes a notable exception.
\end{abstract}

Conclusions: The primary endpoint did not differ significantly between the groups. The secondary outcomes and post hoc analyses warrant additional studies with regard to the potential beneficial effect of glutamate on postischemic myocardial recovery. (J Thorac Cardiovasc Surg 2012;144:922-30)

f Supplemental material is available online.

Adverse outcomes after coronary artery bypass grafting $(\mathrm{CABG})$ is closely related to postoperative heart failure precipitated by ischemia and myocardial infarction. ${ }^{1-3}$

From the Department of Cardiothoracic Surgery and Cardiothoracic Anesthesia, ${ }^{a}$ University Hospital Örebro, Örebro University, Örebro, Sweden; Division of Cardiovascular Medicine, ${ }^{\mathrm{b}}$ Department of Cardiothoracic Surgery and Cardiothoracic Anesthesia, Linköping University Hospital, Linköping University, Linköping, Sweden; and Department of Cardiothoracic Surgery, ${ }^{\mathrm{c}}$ Cardiothoracic Anesthesia Blekinge Hospital, Karlskrona, Sweden.

This study was supported by the Swedish Heart-Lung Foundation (grant 20030595), Capio Research Foundation (grants 2005-1021 and 2006-1203), Linköping University, Östergötlands Läns Landsting, and Örebro Läns Landsting.

Disclosures: Authors have nothing to disclose with regard to commercial support.

${ }^{\dagger}$ Deceased.

Received for publication Dec 27, 2011; revisions received April 13, 2012; accepted for publication May 17, 2012; available ahead of print June 21, 2012.

Address for reprints: Rolf Svedjeholm, MD, PhD, Department of Cardiothoracic Surgery, Linköping University Hospital, Linköping SE-581 85, Sweden (E-mail: rolf. svedjeholm@lio.se).

$0022-5223 / \$ 36.00$

Copyright (c) 2012 by The American Association for Thoracic Surgery

http://dx.doi.org/10.1016/j.jtcvs.2012.05.066
Glutamate has been claimed to protect the heart from ischemia and facilitate metabolic and hemodynamic recovery after ischemic insults. ${ }^{4-7}$ The clinical usefulness of glutamate has not been tested in randomized clinical trials, although glutamate enhancement of cardioplegic solutions has been advocated to protect the heart during cardioplegic arrest. $^{7}$ Intravenous infusion provides the opportunity to supply the heart with substrate during the preoperative and postoperative phases. With the latter approach, encouraging results have been achieved in high-risk $\mathrm{CABG}$, in both study populations and clinical practice. ${ }^{8-11}$ From this experience, the GLUTAmate for Metabolic Intervention in Coronary Surgery (GLUTAMICS) trial was initiated. The primary aim of the present study was to test the hypothesis that intravenous glutamate infusion given in association with CABG for acute coronary syndrome can reduce mortality and prevent or mitigate myocardial injury and postoperative heart failure. The primary clinical trial registration was 2003 Swedish Medical Product Agency Dnr 151: 2003/70403, and the secondary registration was ClinicalTrials.gov Identifier HUNCT00489827UH UR. 


\section{Abbreviations and Acronyms \\ $\mathrm{CABG}=$ coronary artery bypass graft \\ $\mathrm{CCS}=$ Canadian Cardiovascular Society \\ $\mathrm{CPB}=$ cardiopulmonary bypass \\ ICU = intensive care unit \\ NSTEMI $=$ non-ST-segment elevation myocardial infarction}

The secondary endpoints covered the postoperative hemodynamic state, including the treatment and severity of postoperative heart failure, myocardial ischemia and injury, renal function, and neurologic safety issues (see the Appendix).

The main safety endpoints included postoperative mortality and stroke. As an initial safety measure, S100 calcium binding protein B (S-100B) was analyzed in cohort of 70 patients to detect potential subclinical neurologic injury. ${ }^{14}$ The Swedish Medical Products Agency requested surveillance and unblinding in cases of computed tomography-verified stroke within 24 hours of surgery, mortality, and suspected unexpected serious adverse reactions. Before unblinding was done, the case was reviewed by the Clinical Endpoints Committee if suspected circulatory problems had occurred.

All adverse events were registered and are reported in the Appendix. External monitoring of all key data, adverse events, and unblinding procedures was done by an independent professional monitoring team.

\section{Patients}

We recruited patients from October 4, 2005 to November 12, 2009 from 3 Swedish Cardiac Surgery Centers. The inclusion criteria were coronary artery bypass surgery for acute coronary syndrome. Patients were considered for study inclusion if they were scheduled for emergent or urgent surgery because of unstable angina, non-ST-segment elevation myocardial infarction (NSTEMI) or unstable symptoms after ST-segment elevation myocardial infarction. The patients were eligible for inclusion regardless of whether the procedure was done on-pump or off-pump or if the patient underwent a simultaneous valve procedure. Subgroup analyses were planned for patients with increasing degrees of unstable angina. The exclusion criteria were informed consent not possible because of a critical condition or another reason, preoperative use of inotropic drugs or mechanical circulatory assist, preoperative dialysis, redo procedure, unexpected intraoperative findings or an event that increased the magnitude of the procedure to overshadow the originally planned operation, age older than 85 years, body weight greater than $125 \mathrm{~kg}$, and food allergy known to have caused flushing, a rash, or asthma.

\section{Study Design}

The GLUTAmate for Metabolic Intervention in Coronary Surgery trial was an investigator-initiated, prospective, randomized, placebo-controlled, double-blind trial with parallel assignment to glutamate or placebo (saline). The trial was externally randomized in variable block sizes, and an external professional statistician was provided with the randomization codes for interim analysis. External monitoring and reporting of adverse events were done according to the Good Clinical Practice standard.

The patients were randomly allocated to blinded intravenous infusion of $0.125 \mathrm{M} \mathrm{L-glutamic}$ acid solution (see the Appendix) or saline at a rate of $1.65 \mathrm{~mL} / \mathrm{kg}$ of body weight per hour beginning at the induction of anesthesia. The dosage of glutamate was determined from studies demonstrating that an infusion rate of 30 to $40 \mathrm{mg}$ glutamate $/ \mathrm{kg}$ of body weight per hour increased arterial whole blood levels by two- to threefold, sufficient to meet the myocardial demands or to saturate the myocardial capacity to extract glutamate from the circulation. ${ }^{12}$ Because the cardioplegiaarrested heart has been reported to leak glutamate rather than to extract exogenous glutamate, the infusions were temporarily stopped during aortic crossclamping. ${ }^{13}$ The infusions were resumed after declamping of the aorta and continued for an additional 2 hours at this rate, after which the infusion rate was halved and an additional $50 \mathrm{~mL}$ infused. The maximum volume infused to any patient was $500 \mathrm{~mL}$ of study solution. The key study data were prospectively recorded in a case report form (see the Appendix).

\section{Endpoints}

The primary endpoint was a composite of postoperative mortality $(\leq 30$ days), perioperative myocardial infarction, and left ventricular heart failure in association with weaning from cardiopulmonary bypass (CPB) or after completion of off-pump coronary artery bypass surgery. The primary endpoint was positive if 1 of the criteria was fulfilled.

\section{Clinical Endpoints Committee}

Because of the lack of generally accepted criteria for postoperative heart failure in association with cardiac surgery, a blinded Clinical Endpoints Committee relying on prespecified criteria was considered necessary. ${ }^{15-17}$ All patients with suspected postoperative heart failure, as determined by the mixed venous oxygen saturation and other hemodynamic data, the use of inotropic drugs or mechanical circulatory support, an extended intensive care unit (ICU) stay, and circulatory problems reported by anesthesiologists or surgeons in the clinical database, were reviewed. The committee also decided whether events leading to death were cardiac in origin. The details are given in the Appendix.

\section{Definitions}

Postoperative mortality was defined as mortality within 30 days of surgery. Hospital mortality was defined as mortality during the first hospitalization period, including the hospital stay at the referral hospital after discharge from the cardiac surgical unit. A cardiac cause of death was assessed by the Endpoints Committee.

Postoperative heart failure was categorized as heart failure evident at weaning from $\mathrm{CPB}$ or late circulatory failure presenting after apparently uncomplicated weaning. Late circulatory failure was classified as cardiac or noncardiac in origin. Prespecified criteria (available in the Appendix) were used to determine whether heart failure was present. Severe circulatory failure was defined as heart failure leading to death or requiring an ICU stay of 48 hours or longer with intra-aortic balloon pump for 24 hours or longer or inotropic agents in dosages according to the Appendix criteria for 24 hours or longer.

Perioperative myocardial infarction was defined by prespecified criteria using troponin-T and creatine kinase-muscle brain isoenzyme according to the Appendix.

\section{Clinical Management}

The procedures were performed by 26 consultant surgeons and 36 consultant anesthesiologists. Details of the surgical and anesthesiologic management are listed in the Appendix and Table 1.

\section{Statistical Analysis}

The sample size determination $(80 \%$ power; $P<.05)$ according to the clinical results at Linköping University Hospital from 1995 to 2000 suggested that 2214 patients would be required with regard to the primary endpoint, assuming a $30 \%$ reduction of events occurring in $12 \%$ of untreated patients. An interim analysis was planned to occur after the inclusion of 800 patients. The trial was terminated after the interim analysis because the prespecified stopping criteria per protocol had been fulfilled (see the Appendix). The specific reasons included no absolute difference in favor of glutamate with regard to 
TABLE 1. Preoperative and intraoperative data for whole study population

\begin{tabular}{|c|c|c|}
\hline Variable & $\begin{array}{c}\text { Placebo } \\
(\mathrm{n}=\mathbf{4 3 3})\end{array}$ & $\begin{array}{c}\text { Glutamate } \\
(\mathrm{n}=\mathbf{4 2 8})\end{array}$ \\
\hline Age (y) & $68 \pm 9$ & $68 \pm 9$ \\
\hline Female gender & $18.9 \%(82)$ & $17.5 \%(75)$ \\
\hline $\operatorname{BMI}\left(\mathrm{kg} / \mathrm{m}^{2}\right)$ & $27 \pm 4$ & $27 \pm 4$ \\
\hline euroSCORE* & $5.0 \pm 2.8$ & $5.3 \pm 2.8$ \\
\hline Plasma creatinine $(\mu \mathrm{mol} / \mathrm{L})$ & $97 \pm 29$ & $98 \pm 27$ \\
\hline COPD & $5.4 \%(23)$ & $7.6 \%(33)$ \\
\hline Hypertension & $59.8 \%(259)$ & $56.4 \%(241)$ \\
\hline Diabetes & $25.4 \%(110)$ & $23.9 \%(102)$ \\
\hline Cerebrovascular disease & $8.1 \%(35)$ & $8.5 \%(36)$ \\
\hline Extracardiac arterial disease & $9.3 \%(40)$ & $13.9 \%(59)$ \\
\hline \multicolumn{3}{|l|}{ Braunwald class } \\
\hline NSTEMI & $16.9 \%(73)$ & $14.3 \%(61)$ \\
\hline IB & $10.8 \%(47)$ & $12.9 \%(55)$ \\
\hline IC & $6.0 \%(26)$ & $8.4 \%(36)$ \\
\hline IIB & $12.2 \%(53)$ & $10.0 \%(43)$ \\
\hline IIC & $29.1 \%(126)$ & $31.5 \%(135)$ \\
\hline IIIB & $11.1 \%(48)$ & $9.1 \%(39)$ \\
\hline IIIC & $13.9 \%(60)$ & $13.6 \%(58)$ \\
\hline STEMI & $0.0 \%(0)$ & $0.2 \%(1)$ \\
\hline \multicolumn{3}{|l|}{ CCS class } \\
\hline Unassessable & $29.6 \%(128)$ & $26.9 \%(115)$ \\
\hline III & $13.6 \%(59)$ & $17.3 \%(74)$ \\
\hline IV & $55.9 \%(242)$ & $54.4 \%(233)$ \\
\hline Angina at rest $<48 \mathrm{~h}$ preoperatively & $23.6 \%(102)$ & $19.2 \%(82)$ \\
\hline Three-vessel disease & $78.9 \%(342)$ & $77.5 \%(332)$ \\
\hline Left main stem stenosis & $35.2 \%(152)$ & $42.6 \%(182)$ \\
\hline \multicolumn{3}{|l|}{ Recent myocardial infarction } \\
\hline $0-24 \mathrm{~h}$ & $1.2 \%(5)$ & $0.2 \%(1)$ \\
\hline $1-7 \mathrm{~d}$ & $22.6 \%(98)$ & $24.4 \%(104)$ \\
\hline $8-21 \mathrm{~d}$ & $37.2 \%(161)$ & $40.7 \%(174)$ \\
\hline Intravenous nitroglycerine preoperatively & $8.5 \%(37)$ & $8.9 \%(38)$ \\
\hline ST-segment depression $>1 \mathrm{~mm}$ in $\mathrm{OR} \dagger$ & $6.0 \%(26)$ & $5.3 \%(23)$ \\
\hline \multicolumn{3}{|l|}{ LV dysfunction } \\
\hline Moderate & $14.1 \%(61)$ & $14.8 \%(63)$ \\
\hline Severe & $5.1 \%(22)$ & $3.7 \%(16)$ \\
\hline Emergency procedure & $5.5 \%(24)$ & $4.2 \%(18)$ \\
\hline Other operation than isolated CABG & $4.6 \%(20)$ & $3.7 \%(16)$ \\
\hline Concomitant aortic valve procedure & $2.1 \%(9)$ & $1.4 \%(6)$ \\
\hline Concomitant mitral valve procedure & $2.1 \%(9)$ & $1.4 \%(6)$ \\
\hline Other concomitant procedure & $0.4 \%(2)$ & $0.9 \%$ \\
\hline OPCAB & $2.1 \%(9)$ & $3.5 \%(15)$ \\
\hline Cold crystalloid cardioplegia & $36.3 \%(157)$ & $35.0 \%(150)$ \\
\hline Cold blood cardioplegia & $63.7 \%(276)$ & $65.0 \%(278)$ \\
\hline CPB time $(\min )$ & $83 \pm 30$ & $84 \pm 31$ \\
\hline Aortic crossclamp time (min) & $54 \pm 22$ & $53 \pm 21$ \\
\hline Use of LITA & $95.8 \%(415)$ & $95.3 \%(408)$ \\
\hline Bypass (n) & $3.8 \pm 1.2$ & $3.8 \pm 1.2$ \\
\hline
\end{tabular}

Data presented as mean \pm standard deviation or proportions with numbers in parentheses. $B M I$, Body mass index; $C A B G$, coronary artery bypass grafting; $C C S$, Canadian Cardiovascular Society; $C O P D$, chronic obstructive pulmonary disease; $C P B$, cardiopulmonary bypass; euroSCORE, European System for Cardiac Operative Risk Evaluation; LITA, left internal thoracic artery; $L V$, left ventricular (dysfunction according to echocardiographic findings); NSTEMI, non-ST-segment elevation myocardial infarction; $O R$, operating room; $O P C A B$, off-pump coronary artery bypass; STEMI, ST-segment elevation myocardial infarction. *Additive euroSCORE. $\dagger$ Electrocardiographic changes in operating room before institution of CPB. the primary endpoint and no statistically significant differences regarding the markers of myocardial injury or renal function in favor of glutamate at the interim analysis.

Two-sided significance tests with Fisher's exact test for categorical data and Student's $t$-test or the Mann-Whitney $U$ test for continuous variables, as appropriate, were used for the comparisons between the study groups. The results are presented as percentages, the mean \pm standard deviation, or median and interquartile range. The multivariate analysis and relative risk calculations are described and presented in the Appendix (Tables E1 and E2). Adjustment for multiple testing was not performed. Statistical analyses were performed using computerized statistical packages (Statistica, version 9.1, StatSoft, Tulsa, Okla, and SPSS Statistics, version 18, SPSS, Chicago, Ill).

\section{Ethical Review}

After the patients provided written informed consent, they were enrolled in the study. The study was performed according to the Helsinki Declaration of Human Rights and was approved by the Swedish Medical Products Agency (151:2003/70403) and the Regional Ethical Review Board in Linköping (M76-05).

\section{RESULTS}

During the study period, 2087 patients underwent surgery for acute coronary syndrome. Of these, 1064 were assessed for eligibility, 865 were randomized, and 861 were included in the study (Figure 1).

Four patients were excluded intraoperatively because of intraoperative findings or events that overshadowed the originally planned operation. Of the 4 patients, 2 were in the glutamate group because of replacement of the ascending aorta and 2 were in the control group because of massive air embolism from the pump and protracted extraordinary bleeding complications. The data of the patients not included in the present study who underwent surgery for acute coronary syndrome during the study period are presented in the Appendix (Tables E3 and E4).

The baseline data for the whole study population $(\mathrm{n}=861)$ are listed in Table 1 . The groups were evenly distributed, with the exception of significantly more patients with extracardiac arterial disease $(13.9 \%$ vs $9.3 \%$; $P=.04)$ and left main stenosis $(42.6 \%$ vs $35.2 \%$; $P=.03)$ in the glutamate group.

The primary and secondary endpoints for the whole study population are listed in Table 2. The incidence of the composite primary endpoint was $7.3 \%$ in the glutamate group and $5.8 \%$ in the control group. The 30-day all-cause mortality was $0.9 \%$ in the glutamate group and $1.2 \%$ in the control group. None of these differences were statistically significant.

A trend was seen in the secondary endpoints toward fewer patients in the glutamate group requiring an intraaortic balloon pump on admission to the ICU ( $0 \%$ vs $1.2 \% ; P=.06$ ) and fewer patients who were hemodynamically unstable at surgery completion despite inotropic drugs or the need for an intra-aortic balloon pump $(0.3 \%$ vs $1.8 \% ; P=.07)$. 


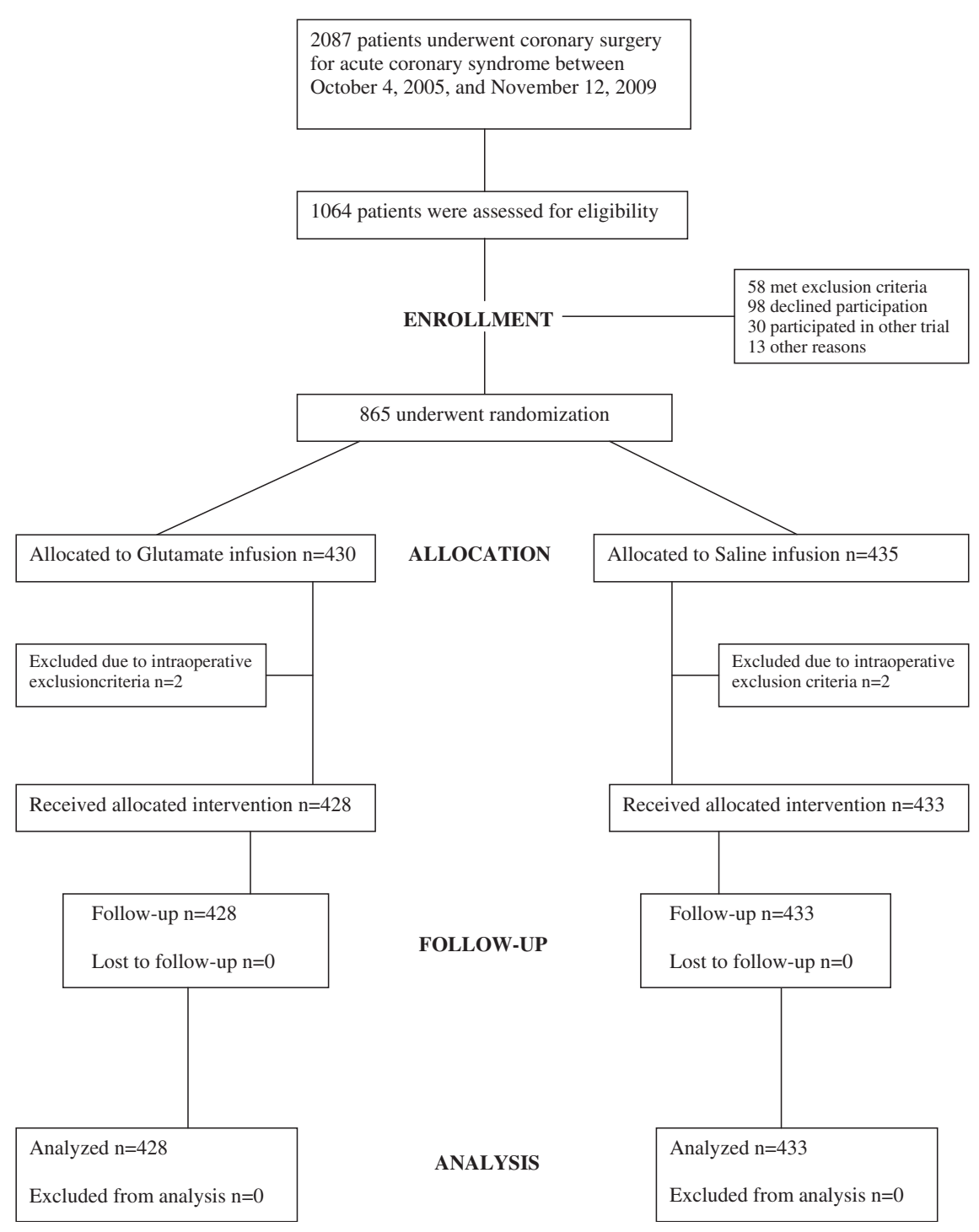

FIGURE 1. Consort flow chart.

The ICU stay or ventilator duration did not differ between the groups; however, the patients with left ventricular failure at weaning from CPB had a significantly shorter median ICU stay (median, 25 hours; range, 18-57; vs 92 hours; range, $41-139 ; P=.02$ ) and ventilator treatment (median, 5.0 hours; range, 3.3-8.0; vs median, 7.4 hours; range, $5.8-49 ; P=.02$ ) if they had received glutamate infusion (Figure E1). In the cohort with left ventricular failure at weaning from $\mathrm{CPB}$, the postoperative lactate level measured 5 minutes after protamine administration was significantly lower in the glutamate group $(1.7 \pm 0.5$ vs $2.5 \pm 1.0 \mathrm{mmol} / \mathrm{L} ; P=.004)$.

The in-hospital or 30-day cardiac mortality was $0.2 \%$ in the glutamate group and $0.9 \%$ the control group $(P=.37)$. No significant differences were found regarding the incidence of postoperative stroke.
Subgroup Analysis of Patients With Canadian Cardiovascular Society Class IV Angina Undergoing Isolated CABG

The baseline data for patients with Canadian Cardiovascular Society (CCS) class IV angina undergoing isolated CABG $(n=458)$ are listed in Table 3 . The groups were evenly distributed, with the exception of significantly more patients with left main stenosis $(44.4 \%$ vs $34.3 \%$; $P=.03)$ in the glutamate group. The primary and secondary endpoints are listed in Table 4.

The incidence of the composite primary endpoint was $7.6 \%$ in the glutamate group and $7.8 \%$ in the control group. The 30-day mortality was $0.9 \%$ in the glutamate group and $1.3 \%$ in the control group. None of these differences were statistically significant. 
TABLE 2. Primary and secondary endpoints for whole study population

\begin{tabular}{|c|c|c|c|}
\hline Endpoint & $\begin{array}{c}\text { Placebo } \\
(n=433)\end{array}$ & $\begin{array}{c}\text { Glutamate } \\
(n=428)\end{array}$ & $\begin{array}{c}P \\
\text { value }\end{array}$ \\
\hline Primary & $25(5.8 \%)$ & $31(7.3 \%)$ & .41 \\
\hline $\begin{array}{l}\text { LV failure at weaning from } \\
\text { CPB }\end{array}$ & $18(4.2 \%)$ & $20(4.7 \%)$ & .74 \\
\hline $\begin{array}{l}\text { Perioperative myocardial } \\
\text { infarction }\end{array}$ & $6(1.4 \%)$ & $11(2.6 \%)$ & .23 \\
\hline 30-d Mortality & $5(1.2 \%)$ & $4(0.9 \%)$ & 1.0 \\
\hline \multicolumn{4}{|l|}{ Secondary } \\
\hline Inotropes at weaning & $53(12.3 \%)$ & $59(13.8 \%)$ & .54 \\
\hline Epinephrine & $21(4.9 \%)$ & $19(4.5 \%)$ & .78 \\
\hline Milrinone & $43(10.0 \%)$ & $40(9.4 \%)$ & .78 \\
\hline Other & $9(2.1 \%)$ & $13(3.0 \%)$ & .37 \\
\hline $\mathrm{SvO}_{2}$ at weaning $(\%)$ & $72.2 \pm 7.3$ & $72.0 \pm 7.6$ & .69 \\
\hline $\mathrm{SAP}$ at weaning $(\mathrm{mm} \mathrm{Hg})$ & $85 \pm 17$ & $85 \pm 18$ & .93 \\
\hline $\begin{array}{l}\alpha \text {-Lactate } \mathrm{mmol} / \mathrm{L} 5 \mathrm{~min} \\
\text { after protamine }\end{array}$ & $1.7 \pm 0.6$ & $1.6 \pm 0.6$ & .07 \\
\hline \multicolumn{4}{|l|}{$\begin{array}{l}\text { Hemodynamic state at } \\
\text { surgery completion* }\end{array}$} \\
\hline Stable without inotropes & $310(77.4 \%)$ & $302(78.5 \%)$ & .73 \\
\hline Stable with inotropes & $78(19.8 \%)$ & $87(22.3 \%)$ & .38 \\
\hline $\begin{array}{l}\text { Unstable with inotropes/ } \\
\text { IABP }\end{array}$ & $7(1.8 \%)$ & $1(0.3 \%)$ & .07 \\
\hline $\begin{array}{l}\text { Inotropes on admission } \\
\text { to ICU }\end{array}$ & $58(13.4 \%)$ & $70(16.4 \%)$ & .25 \\
\hline Epinephrine & $31(7.2 \%)$ & $36(8.4 \%)$ & .49 \\
\hline Milrinone & $29(6.7 \%)$ & $31(7.2 \%)$ & .75 \\
\hline Other & $7(1.7 \%)$ & $15(3.5 \%)$ & .78 \\
\hline \multicolumn{4}{|l|}{$\begin{array}{l}\text { Late postoperative } \\
\text { circulatory failure }\end{array}$} \\
\hline Cardiac & $8(1.8 \%)$ & $10(2.3 \%)$ & .64 \\
\hline Noncardiac & $15(3.5 \%)$ & $7(1.7 \%)$ & .13 \\
\hline Severe circulatory failure & $18(4.2 \%)$ & $10(2.3 \%)$ & .18 \\
\hline Primary cardiac & $15(3.5 \%)$ & $8(1.9 \%)$ & .20 \\
\hline $\begin{array}{l}\mathrm{CK}-\mathrm{MB}(\mu \mathrm{g} / \mathrm{L}) \text { day } 1 \\
\text { postoperatively }\end{array}$ & $14(10-23)$ & $14(10-23)$ & .81 \\
\hline $\begin{array}{l}\text { Troponin- } \mathrm{T}(\mu \mathrm{g} / \mathrm{L}) \text { day } 3-4 \\
\text { postoperatively }\end{array}$ & $0.24(0.13-0.52)$ & $0.27(0.16-0.57)$ & .07 \\
\hline $\begin{array}{l}\text { Plasma cystatin } \mathrm{C}(\mathrm{mg} / \mathrm{L}) \\
\text { day 3-4 postoperatively }\end{array}$ & $1.3 \pm 0.5$ & $1.3 \pm 0.5$ & .21 \\
\hline $\begin{array}{l}\text { Peak plasma creatinine } \\
\quad(\mu \mathrm{mol} / \mathrm{L})\end{array}$ & $106 \pm 50$ & $106 \pm 50$ & .86 \\
\hline Dialysis postoperatively & $6(1.4 \%)$ & $2(0.5 \%)$ & .29 \\
\hline ICU duration (h) & $21(17-23)$ & $21(17-23)$ & .65 \\
\hline Ventilator duration (h) & $4.5(3.1-6.8)$ & $4.5(3.0-6.5)$ & .39 \\
\hline $\begin{array}{l}\text { Postoperative atrial } \\
\text { fibrillation }\end{array}$ & $152(35.2 \%)$ & $147(34.4 \%)$ & .83 \\
\hline $\begin{array}{l}\text { Reoperation for bleeding/ } \\
\text { tamponade }\end{array}$ & $21(4.8 \%)$ & $22(5.1 \%)$ & .88 \\
\hline
\end{tabular}

(Continued)

Regarding the secondary endpoints, significantly fewer patients in the glutamate group developed severe circulatory failure $(1.3 \%$ vs $6.9 \% ; P=.004)$.
TABLE 2. Continued

\begin{tabular}{llcr}
\hline \multicolumn{1}{c}{ Endpoint } & $\begin{array}{c}\text { Placebo } \\
(\mathbf{n}=\mathbf{4 3 3})\end{array}$ & $\begin{array}{c}\text { Glutamate } \\
(\mathbf{n}=\mathbf{4 2 8})\end{array}$ & $\begin{array}{c}\boldsymbol{P} \\
\text { value }\end{array}$ \\
\hline $\begin{array}{l}\text { Stroke within } 24 \mathrm{~h} \\
\text { postoperatively }\end{array}$ & $6(1.4 \%)$ & $4(0.9 \%)$ & .75 \\
$\begin{array}{l}\text { Stroke during hospital stay } \\
\text { Hospital mortality }\end{array}$ & $6(1.4 \%)$ & $8(1.9 \%)$ & .60 \\
$\begin{array}{l}\text { Cardiac mortality } \\
\text { (in-hospital or 30-d) }\end{array}$ & $6(1.4 \%)$ & $4(0.9 \%)$ & .75 \\
\hline $\begin{array}{l}\text { Data presented as median with interquartile range in parentheses, mean } \pm \text { standard } \\
\text { deviation, or numbers with percentages in parentheses. } C K-M B, \text { Creatine kinase- } \\
\text { muscle brain isoenzyme; } C P B, \text { cardiopulmonary bypass; } I A B P, \text { intra-aortic balloon }\end{array}$ \\
$\begin{array}{l}\text { pump; } I C U \text {, intensive care unit; } L V \text {, left ventricular; } S A P, \text { systolic arterial pressure; } \\
\mathrm{S} \mathrm{O}_{2} \text {, mixed venous oxygen saturation. } * \text { Data available from 2 largest participating } \\
\text { centers. }\end{array}$
\end{tabular}

In the multivariate analysis (Table E1), glutamate infusion was associated with a reduced risk of developing severe circulatory failure (odds ratio, $0.2 ; 95 \%$ confidence interval, $0.04-0.72 ; P=.02$ ). The addition of postoperative bleeding or tamponade, the most common causes of late circulatory failure of noncardiac origin, had no effect on the final model. Intravenous glutamate infusion also remained significantly associated with a reduced risk of developing severe circulatory failure if the final model was adjusted for the European System for Cardiac Operative Risk Evaluation.

In CCS class IV patients, the postoperative lactate level measured 5 minutes after protamine administration was significantly lower in the glutamate group $(1.6 \pm 0.5$ vs $1.8 \pm$ $0.6 \mathrm{mmol} / \mathrm{L} ; P=.006$ ).

\section{Other Subgroups}

No statistically significant difference regarding the primary endpoint was found in the prespecified subgroups. The effect of glutamate on the risk of developing severe circulatory failure postoperatively in other risk groups was calculated as the relative risk (Table E2). A relative risk reduction exceeding $50 \%$ was seen in most categories undergoing isolated $\mathrm{CABG}$, with the exception of patients with diabetes and those with a low event rate having NSTEMI only without a history of angina.

\section{Adverse Events}

The adverse events are presented in Table E5. The incidence of serious or nonserious adverse events did not differ significantly between the study groups.

\section{DISCUSSION}

No significant between-group differences were found regarding the composite primary endpoint or markers for myocardial injury or postoperative renal function. The latter finding implied that the prespecified stopping criteria were fulfilled at the interim analysis; hence, the study was terminated. Subsequent analysis revealed significant 
TABLE 3. Preoperative and intraoperative data for patients with CCS class IV angina undergoing isolated CABG

\begin{tabular}{|c|c|c|}
\hline Variable & $\begin{array}{c}\text { Placebo } \\
(\mathbf{n}=\mathbf{2 3 3})\end{array}$ & $\begin{array}{c}\text { Glutamate } \\
(\mathbf{n}=\mathbf{2 2 5})\end{array}$ \\
\hline Age (y) & $68 \pm 9$ & $68 \pm 9$ \\
\hline Female gender & $19.7 \%(46)$ & $17.3 \%(39)$ \\
\hline BMI $\left(\mathrm{kg} / \mathrm{m}^{2}\right)$ & $27 \pm 4$ & $27 \pm 4$ \\
\hline euroSCORE* & $5.2 \pm 3.0$ & $5.4 \pm 2.9$ \\
\hline Plasma creatinine $(\mu \mathrm{mol} / \mathrm{L})$ & $101 \pm 35$ & $101 \pm 26$ \\
\hline COPD & $5.6 \%(13)$ & $9.0 \%(20)$ \\
\hline Hypertension & $60.6 \%(141)$ & $57.7 \%(130)$ \\
\hline Diabetes & $27.0 \%(63)$ & $23.6 \%(53)$ \\
\hline Cerebrovascular disease & $8.6 \%(20)$ & $8.9 \%(20)$ \\
\hline Extracardiac arterial disease & $10.7 \%(25)$ & $14.5 \%(33)$ \\
\hline \multicolumn{3}{|l|}{ Braunwald class } \\
\hline NSTEMI & $4.7 \%(11)$ & $3.1 \%(7)$ \\
\hline IB & $4.7 \%(11)$ & $4.9 \%(11)$ \\
\hline IC & $2.1 \%(5)$ & $3.1 \%(7)$ \\
\hline IIB & $13.3 \%(31)$ & $12.4 \%(28)$ \\
\hline IIC & $33.0 \%(77)$ & $37.3 \%(84)$ \\
\hline IIIB & $17.2 \%(40)$ & $16.9 \%(38)$ \\
\hline IIIC & $24.9 \%(58)$ & $22.2 \%(50)$ \\
\hline STEMI & $0.0 \%(0)$ & $0.0 \%(0)$ \\
\hline Angina at rest $<48 \mathrm{~h}$ preoperatively & $38.2 \%(89)$ & $31.2 \%(70)$ \\
\hline Three-vessel disease & $77.7 \%(181)$ & $77.8 \%(175)$ \\
\hline Left main stem stenosis & $34.3 \%(80)$ & $44.4 \%(100)$ \\
\hline \multicolumn{3}{|l|}{ Recent myocardial infarction } \\
\hline $0-24 \mathrm{~h}$ & $1.7 \%(4)$ & $0.4 \%(1)$ \\
\hline $1-7 \mathrm{~d}$ & $19.3 \%(45)$ & $21.3 \%(48)$ \\
\hline $8-21 \mathrm{~d}$ & $37.8 \%(88)$ & $41.3 \%(93)$ \\
\hline Intravenous nitroglycerine preoperatively & $13.7 \%(32)$ & $13.3 \%(30)$ \\
\hline ST-segment depression $>1 \mathrm{~mm}$ in $\mathrm{OR} \dagger$ & $9.0 \%(21)$ & $6.0 \%(14)$ \\
\hline \multicolumn{3}{|l|}{ LV dysfunction } \\
\hline Moderate & $15.0 \%(35)$ & $13.3 \%(30)$ \\
\hline Severe & $6.0 \%(14)$ & $4.9 \%(11)$ \\
\hline Emergency procedure & $9.0 \%(21)$ & $5.3 \%(12)$ \\
\hline OPCAB & $3.0 \%(7)$ & $3.1 \%(7)$ \\
\hline Cold crystalloid cardioplegia & $43.8 \%(102)$ & $42.9 \%(97)$ \\
\hline Cold blood cardioplegia & $56.2 \%(131)$ & $57.1 \%(128)$ \\
\hline CPB time (min) & $81 \pm 25$ & $83 \pm 30$ \\
\hline Aortic crossclamp time (min) & $53 \pm 17$ & $53 \pm 17$ \\
\hline Use of LITA & $97.4 \%(227)$ & $96.0 \%(216)$ \\
\hline Bypass (n) & $3.8 \pm 1.2$ & $3.8 \pm 1.2$ \\
\hline
\end{tabular}

Data presented as mean \pm standard deviation or proportions with numbers in parentheses. $B M I$, Body mass index; $C A B G$, coronary artery bypass grafting; $C C S$, Canadian Cardiovascular Society; $C O P D$, chronic obstructive pulmonary disease; $C P B$, cardiopulmonary bypass; euroSCORE, European System for Cardiac Operative Risk Evaluation; LITA, left internal thoracic artery; $L V$, left ventricular (dysfunction according to echocardiographic findings); NSTEMI, non-ST-segment elevation myocardial infarction; $O R$, operating room; $O P C A B$, off-pump coronary artery bypass. *Additive euroSCORE. $\dagger$ Electrocardiographic changes in operating room before institution of $\mathrm{CPB}$.

between-group differences in favor of the glutamate group regarding the secondary endpoints related to hemodynamic recovery.

Although the trial findings were negative, the secondary outcomes and post hoc analyses suggested that additional clinical evaluation of intravenous glutamate would be warranted. The results were compatible with the hypothesis that glutamate mitigates postoperative heart failure by enhancing myocardial recovery. The incidence of left ventricular failure at weaning from CPB did not differ between the groups; however, the post hoc analysis revealed that patients with weaning problems treated with glutamate had substantially shorter ICU stay and ventilator treatment (Figure E1). In patients with more severe ischemia (CCS class IV angina) undergoing isolated CABG, significantly fewer developed severe circulatory failure in the glutamate group. Multivariate analysis identified intravenous glutamate infusion as the only variable associated with a reduced incidence of severe circulatory failure. This effect with a relative risk reduction exceeding $50 \%$ was found in most risk groups undergoing isolated $\mathrm{CABG}$ in the present trial with the exception of patients with diabetes and those with a low event rate having NSTEMI only as the first manifestation of coronary artery disease. The relative risk calculations should be interpreted cautiously owing to the low event rate, but they provide guidance for future studies (Table E2).

The arterial lactate levels differed during early reperfusion and, although the difference overall was minor, it could reflect clinically more significant differences detected in sicker patients, such as those with left ventricular failure at weaning from $\mathrm{CPB}$.

Patients with acute coronary syndrome were chosen for the present trial because they represented the largest risk group in our practice. Almost $30 \%$ of the patients in our study were unassessable regarding CCS class because of NSTEMI with a brief or uncertain history of angina or NSTEMI as the only manifestation of coronary artery disease. Patients requiring emergency surgery were not eligible because of ethical reasons, further contributing to the lower than anticipated event rates. Thus, it is questionable whether the cohort studied can be regarded as a high-risk group. Originally, the trial was intended for patients with unstable angina; thus, patients with CCS class IV angina undergoing isolated CABG were analyzed separately to address this issue. The multivariate analysis was added to adjust for other risk factors associated with the development of severe circulatory failure.

Intravenous glutamate infusion according to our protocol could influence the postoperative outcome by 2 different biochemical mechanisms. First, glutamate could improve myocardial tolerance to ischemia by facilitating anaerobic metabolism during ischemia. ${ }^{4,5,7}$ In the present study, no clinical evidence for this mechanism was found.

The second mechanism by which glutamate could influence the postoperative outcome after coronary surgery is related to the anaplerotic role of glutamate. Owing to its role in the malate-aspartate shuttle, glutamate contributes to replenishment of the Krebs cycle intermediates lost during ischemia. ${ }^{5,7}$ The lack of effect in patients with diabetes could be explained by recently demonstrated downregulation of 
TABLE 4. Primary and secondary endpoints for patients with CCS class IV angina undergoing isolated CABG

\begin{tabular}{|c|c|c|c|}
\hline Endpoint & $\begin{array}{l}\text { Placebo } \\
(\mathbf{n}=\mathbf{2 3 3})\end{array}$ & $\begin{array}{l}\text { Glutamate } \\
(\mathbf{n}=225)\end{array}$ & $\begin{array}{c}P \\
\text { value }\end{array}$ \\
\hline Primary & $18(7.8 \%)$ & $17(7.6 \%)$ & 1.0 \\
\hline $\begin{array}{l}\text { LV failure at weaning from } \\
\text { CPB }\end{array}$ & $12(5.2 \%)$ & $12(5.3 \%)$ & 1.0 \\
\hline $\begin{array}{l}\text { Perioperative myocardial } \\
\text { infarction }\end{array}$ & $5(2.2 \%)$ & $6(2.7 \%)$ & .77 \\
\hline 30-d Mortality & $3(1.3 \%)$ & $2(0.9 \%)$ & 1.0 \\
\hline \multicolumn{4}{|l|}{ Secondary } \\
\hline Inotropes at weaning & $28(12.0 \%)$ & $25(11.2 \%)$ & .88 \\
\hline Epinephrine & $16(6.9 \%)$ & $11(4.9 \%)$ & .43 \\
\hline Milrinone & $24(10.3 \%)$ & $14(6.3 \%)$ & .13 \\
\hline Other & $4(1.7 \%)$ & $6(2.7 \%)$ & .53 \\
\hline $\mathrm{SvO}_{2} \%$ at weaning & $71.7 \pm 7.1$ & $71.6 \pm 7.6$ & .82 \\
\hline SAP weaning $(\mathrm{mm} \mathrm{Hg})$ & $83 \pm 16$ & $83 \pm 18$ & .96 \\
\hline $\begin{array}{l}\alpha \text {-Lactate } \mathrm{mmol} / \mathrm{l} 5 \mathrm{~min} \\
\text { after protamine }\end{array}$ & $1.8 \pm 0.6$ & $1.6 \pm 0.5$ & .006 \\
\hline \multicolumn{4}{|l|}{$\begin{array}{l}\text { Hemodynamic state at } \\
\text { surgery completion* }\end{array}$} \\
\hline Stable without inotropes & $186(80.9 \%)$ & $174(79.8 \%)$ & .81 \\
\hline Stable with inotropes & $39(17.0 \%)$ & $43(19.7 \%)$ & .47 \\
\hline $\begin{array}{l}\text { Unstable with inotropes/ } \\
\text { IABP }\end{array}$ & $5(2.2 \%)$ & $1(0.5 \%)$ & .22 \\
\hline $\begin{array}{l}\text { Inotropes on admission } \\
\text { to ICU }\end{array}$ & $34(14.6 \%)$ & $31(13.8 \%)$ & .89 \\
\hline Epinephrine & $22(9.4 \%)$ & $20(8.9 \%)$ & .87 \\
\hline Milrinone & $17(7.3 \%)$ & $11(4.9 \%)$ & .33 \\
\hline Other & $3(1.3 \%)$ & $6(2.7 \%)$ & .33 \\
\hline IABP on admission to ICU & $5(2.1 \%)$ & $0(0 \%)$ & .06 \\
\hline \multicolumn{4}{|l|}{$\begin{array}{l}\text { Late postoperative } \\
\text { circulatory failure }\end{array}$} \\
\hline Cardiac & $7(3.0 \%)$ & $4(1.8 \%)$ & .54 \\
\hline Noncardiac & $11(4.7 \%)$ & $3(1.3 \%)$ & .05 \\
\hline Severe circulatory failure & $16(6.9 \%)$ & $3(1.3 \%)$ & .004 \\
\hline Primary cardiac & $13(5.6 \%)$ & $3(1.3 \%)$ & .02 \\
\hline $\begin{array}{l}\text { CK-MB }(\mu \mathrm{g} / \mathrm{L}) \text { day } 1 \\
\text { postoperatively }\end{array}$ & $15(10-24)$ & $14(10-22)$ & .73 \\
\hline $\begin{array}{l}\text { Troponin- } \mathrm{T}(\mu \mathrm{g} / \mathrm{L}) \text { day } 3-4 \\
\text { postoperatively }\end{array}$ & $0.26(0.14-0.59)$ & $0.26(0.15-0.53)$ & .62 \\
\hline $\begin{array}{l}\text { Plasma cystatin } \mathrm{C}(\mathrm{mg} / \mathrm{L}) \\
\text { day 3-4 postoperatively }\end{array}$ & $1.3 \pm 0.5$ & $1.3 \pm 0.5$ & .30 \\
\hline $\begin{array}{l}\text { Peak plasma creatinine } \\
\quad(\mu \mathrm{mol} / \mathrm{L})\end{array}$ & $112 \pm 60$ & $109 \pm 50$ & .59 \\
\hline Dialysis postoperatively & $6(2.6 \%)$ & $1(0.4 \%)$ & .12 \\
\hline ICU duration (h) & $21(17-24)$ & $20(17-23)$ & .40 \\
\hline Ventilator duration (h) & $4.4(3.1-6.8)$ & $4.3(2.8-6.4)$ & .27 \\
\hline $\begin{array}{l}\text { Postoperative atrial } \\
\text { fibrillation }\end{array}$ & $76(32.6 \%)$ & $81(36.0 \%)$ & .49 \\
\hline $\begin{array}{l}\text { Reoperation for bleeding/ } \\
\text { tamponade }\end{array}$ & $15(6.4 \%)$ & $9(4.0 \%)$ & .30 \\
\hline
\end{tabular}

(Continued)

the mitochondrial glutamate transporter EAAT1, which was associated with increased intracellular glutamate levels and impaired postischemic protection by glutamate in the
TABLE 4. Continued

\begin{tabular}{llcc}
\hline \multicolumn{1}{c}{ Endpoint } & $\begin{array}{c}\text { Placebo } \\
(\mathbf{n}=\mathbf{2 3 3})\end{array}$ & $\begin{array}{c}\text { Glutamate } \\
(\mathbf{n}=\mathbf{2 2 5})\end{array}$ & $\begin{array}{c}\boldsymbol{P} \\
\text { value }\end{array}$ \\
\hline $\begin{array}{l}\text { Stroke within } 24 \mathrm{~h} \\
\text { postoperatively }\end{array}$ & $2(0.8 \%)$ & $2(0.9 \%)$ & 1.0 \\
$\begin{array}{l}\text { Stroke during hospital stay } \\
\text { Hospital mortality }\end{array}$ & $3(1.3 \%)$ & $3(1.3 \%)$ & 1.0 \\
$\begin{array}{l}\text { Cardiac mortality } \\
\text { (in-hospital or 30-d) }\end{array}$ & $5(2.1 \%)$ & $3(1.3 \%)$ & .72 \\
\hline $\begin{array}{l}\text { Data presented as median with the interquartile range in parentheses, mean } \pm \text { stan- } \\
\text { dard deviation, or numbers with percentages in parentheses. } C K-M B, \text { Creatine }\end{array}$ \\
kinase-muscle brain isoenzyme; $C P B$, cardiopulmonary bypass; $I A B P$, intra-aortic \\
balloon pump; $I C U$, intensive care unit; $L V$, left ventricular; $S A P$, systolic arterial \\
pressure; $S v O_{2}$, mixed venous oxygen saturation; $C C S$, Canadian Cardiovascular So- \\
ciety; $C A B G$, coronary artery bypass grafting. *Data available from 2 largest partici- \\
pating centers.
\end{tabular}

diabetic rat heart. ${ }^{18}$ The validity of these observations for humans has been supported by findings in atrial biopsies from humans undergoing $\mathrm{CABG}$, demonstrating mitochondrial dysfunction and a sharply decreased capacity to glutamate-supported respiration in patients with diabetes compared with those without diabetes. ${ }^{19}$

Although not a mechanistic study, the secondary outcomes of the present trial were compatible with enhanced postischemic myocardial recovery in nondiabetic patients undergoing $\mathrm{CABG}$ for unstable angina. This is in agreement with the results of previous studies, suggesting that intravenous glutamate infusion enhances recovery of myocardial metabolism and function after ischemia. ${ }^{8,9,20}$ Promoting recovery represents a different and more appealing concept than the use of inotropic drugs that increase oxygen expenditure, regardless of the state of myocardial recovery. This could explain the encouraging clinical outcomes previously reported with metabolic interventions. ${ }^{10,11}$

Certain study limitations deserve comment. The study was prematurely terminated because the prespecified stopping criteria had been fulfilled; thus, most prespecified subgroups were too small for meaningful analysis. In retrospect, we found that the inclusion of off-pump procedures and operations with concomitant procedures was illadvised, because they added heterogeneity to the trial. This reduced its power because many of the problems encountered were related to surgical technical issues and postoperative bleeding. However, the various uses of cardioplegia had no bearing on the outcomes of the trial and did not influence the multivariate analysis with regard to severe circulatory failure. The criteria used for postoperative heart failure are inevitably debatable. Although this condition is a major cause of postoperative mortality, the generally accepted criteria for this diagnosis are lacking. ${ }^{17}$ To address this issue, we based the criteria on variables documented with regard to outcome and provided the blinded Clinical Endpoints Committee with strict prespecified criteria to minimize bias from individual clinical 
judgement. ${ }^{11,17,21,22}$ In retrospect, the usefulness of the endpoint of left ventricular failure at weaning from CPB is debatable, because it became evident at the Clinical Endpoint Committee meetings that preemptive use of inotropes prevented detection in patients who later developed severe circulatory failure. Also, the duration of intravenous glutamate infusion from the release of aortic crossclamping to weaning might have been too short to influence this endpoint. The secondary endpoint of severe circulatory failure discriminated mild short-lasting heart failure at weaning from CPB from clinically significant heart failure requiring substantial circulatory support and leading to prolonged ICU stay or death. For exploratory purposes, the patients with severe circulatory failure were divided into those with primary cardiac failure and those with heart failure precipitated by extracardiac events such as tamponade or bleeding. The difference in favor of glutamate was significant for primary cardiac failure; however, a trend was also found for fewer patients in the glutamate group having severe heart failure precipitated by extracardiac events in patients with CCS class IV angina undergoing isolated CABG (Table 4). Although the secondary outcomes and subgroup analyses were provisional, even when prespecified, the results should be regarded in the context of current evidence. The treatment of postoperative heart failure is determined by expert opinion, and the need for large studies to assess the optimal method to manage postoperative heart failure has been emphasized. ${ }^{23}$ From the results of the present trial and previous clinical experience, we will continue using glutamate infusion in our practice as an additive or alternative treatment in patients with anticipated or evident heart failure at weaning from CPB. However, additional studies are needed before intravenous glutamate can be generally recommended for promoting postischemic recovery of the heart in cardiac surgery.

A concern with the use of glutamate is that it might act as an excitotoxin under certain conditions and participate in events leading to neurologic damage. ${ }^{14}$ Available data have not demonstrated any increase in clinically evident neurologic injury when glutamate enhanced cardioplegic solutions or intravenous infusions have been used in clinical practice. ${ }^{24,25}$ No evidence of subclinical neurologic injury associated with intravenous glutamate infusion was found in the S100 calcium binding protein B (S-100B) substudy of the present trial, and the present results showed no differences in the neurologic outcome. ${ }^{14}$ Thus, it appears that intravenous glutamate infusions in the dosages used can be safely administered to patients undergoing cardiac surgery.

\section{CONCLUSIONS}

In the present investigator-initiated trial of 861 patients with acute coronary syndrome undergoing CABG, glutamate did not prevent perioperative myocardial infarction or heart failure at weaning from CPB. However, the secondary outcomes and post hoc analyses are compatible with a beneficial effect of glutamate on postischemic myocardial recovery. Patients with problems weaning from CPB had a substantially shorter ICU stay and ventilator treatment if they had received an intravenous glutamate infusion. In patients with more severe ischemia (CCS class IV angina), significantly fewer patients developed severe circulatory failure in the glutamate group. Intravenous glutamate infusion could provide a novel and important method of promoting myocardial recovery after ischemic injury; however, additional studies are required to establish the clinical usefulness.

We would like to acknowledge Olle Eriksson, Department of Computer and Information Science, Linköping University, who provided external statistical expertise for sample size calculation when the trial was designed and interim analysis and final statistical analyses. We are indebted to research nurses Inger Huljebrant, Sara Thybell, Anna Krantz, and Ann-Kristin Olsson for assistance with data collection.

\section{References}

1. O'Connor GT, Birkmeyer JD, Dacey LJ, Quinton HB, Marrin CA, Birkmeyer NJ, et al. Results of a regional study of modes of death associated with coronary artery bypass grafting. Northern New England Cardiovascular Disease Study Group. Ann Thorac Surg. 1998;66:1323-8.

2. Slogoff S, Keats AS. Does perioperative myocardial ischemia lead to postoperative myocardial infarction? Anesthesiology. 1985;62:107-14.

3. Vanky F, Hakanson E, Maros T, Svedjeholm R. Different characteristics of postoperative heart failure after surgery for aortic stenosis and coronary disease Scand Cardiovasc J. 2004;38:152-8.

4. Rau EE, Shine KI, Gervais A, Douglas AM, Amos EC. Enhanced mechanical recovery of anoxic and ischemic myocardium by amino acid perfusion. Am J Physiol. 1979;236:H873-9.

5. Pisarenko OI. Mechanisms of myocardial protection by amino acids: facts and hypotheses. Clin Exp Pharm Physiol. 1996;23:627-33.

6. Engelman RM, Rousou JA, Flack JE, Iyengar J, Kimura Y, Das DK. Reduction of infarct size by systemic amino acid supplementation during reperfusion. $J$ Thorac Cardiovasc Surg. 1991;101:855-9.

7. Lazar HL, Buckberg GD, Manganaro AJ, Becker H. Myocardial energy replenishment and reversal of ischemic damage by substrate enhancement of secondary blood cardioplegia with amino acids during reperfusion. J Thorac Cardiovasc Surg. 1980;80:350-9

8. Pisarenko OI, Lepilin MG, Ivanov VE. Cardiac metabolism and performance during L-glutamic acid infusion in postoperative cardiac failure. Clin Sci. 1986;70:7-12

9. Svedjeholm R, Vanhanen I, Hakanson E, Joachimsson PO, Jorfeldt L, Nilsson L. Metabolic and hemodynamic effects of intravenous glutamate infusion early after coronary operations. J Thorac Cardiovasc Surg. 1996;112:1468-77.

10. Svedjeholm R, Huljebrant I, Hakanson E, Vanhanen I. Glutamate and high-dose glucose-insulin-potassium (GIK) in the treatment of severe cardiac failure after cardiac operations. Ann Thorac Surg. 1995;59:S23-30.

11. Svedjeholm R, Vidlund M, Vanhanen I, Hakanson E. A metabolic protective strategy could improve long-term survival in patients with LV-dysfunction undergoing CABG. Scand Cardiovasc J. 2010;44:45-58.

12. Vanhanen I, Svedjeholm R, Hakanson E, Joachimsson PO, Jorfeldt L, Nilsson L, et al. Assessment of myocardial glutamate requirements early after coronary artery bypass surgery. Scand Cardiovasc J. 1998;32:145-52.

13. Kimose HH, Ravkilde J, Helligs P, Knudsen MA, Thomassen AR, Nielsen TT, et al. Myocardial loss of glutamate after cold chemical cardioplegia and storage in isolated blood-perfused pig hearts. Thorac Cardiovasc Surg. 1993;41:93-100.

14. Vidlund M, Holm J, Hakanson E, Friberg O, Sunnermalm L, Vanky F, et al The S-100B substudy of the GLUTAMICS trial: glutamate infusion not 
associated with sustained elevation of plasma S-100B after coronary surgery. Clin Nutr. 2009;21:358-64.

15. Gillies M, Bellomo R, Doolan L, Buxton B. Bench-to-bedside review: inotropic drug therapy after adult cardiac surgery-a systematic literature review. Crit Care. 2005;9:266-79.

16. Fellahi JL, Parienti JJ, Hanouz JL, Plaud B, Riou B, Ouattara A. Perioperative use of dobutamine in cardiac surgery and adverse cardiac outcome: propensityadjusted analyses. Anesthesiology. 2008;108:979-87.

17. Vanky FB, Hakanson E, Svedjeholm R. Long-term consequences of postoperative heart failure after surgery for aortic stenosis compared with coronary surgery. Ann Thorac Surg. 2007;83:2036-43.

18. Povlsen JA, Lofgren B, Rasmussen LE, Nielsen JM, Norregaard R, Kristiansen SB, et al. Cardioprotective effect of L-glutamate in obese type 2 diabetes mellitus studies on the isolated perfused Zucker diabetic fatty rat heart. Clin Exp Pharmacol Physiol. 2009;36:892-8.

19. Anderson EJ, Kypson AP, Rodriguez E, Anderson CA, Lehr EJ, Neufer PD. Substrate-specific derangements in mitochondrial metabolism and redox balance in the atrium of the type 2 diabetic human heart. J Am Coll Cardiol. 2009;54: 1891-8.
20. Vanhanen I, Hakanson E, Jorfeldt L, Svedjeholm R. Myocardial uptake and release of substrates in patients operated for unstable angina: impact of glutamate infusion. Scand Cardiovasc J. 2003;37:113-20.

21. Svedjeholm R, Hakanson E, Szabo Z. Routine SvO2 measurement after CABG surgery with a surgically introduced pulmonary artery catheter. Eur J Cardiothorac Surg. 1999;16:450-7.

22. Holm J, Hakanson E, Vanky F, Svedjeholm R. Mixed venous oxygen saturation predicts short- and long-term outcome after coronary artery bypass grafting surgery: a retrospective cohort analysis. Br J Anaesth. 2011;107:344-50.

23. Mebazaa A, Pitsis AA, Rudiger A, Toller W, Longrois D, Ricksten SE, et al. Clinical review: practical recommendations on the management of perioperative heart failure in cardiac surgery. Crit Care. 2010;14:201.

24. Loop FD, Higgins TL, Panda R, Pearce G, Estafanous FG. Myocardial protection during cardiac operations: decreased morbidity and lower cost with blood cardioplegia and coronary sinus perfusion. J Thorac Cardiovasc Surg. 1992;104: 608-18.

25. Svedjeholm R, Hakanson E, Szabo Z, Vanky F. Neurological injury after surgery for ischemic heart disease: risk factors, outcome and role of metabolic interventions. Eur J Cardiothorac Surg. 2001;19:611-8. 


\section{APPENDIX}

The study (GLUTAmate for Metabolic Intervention in Coronary Surgery [ClinicalTrials.gov Identifier: NCT00489827]) was approved by the Swedish Medical Products Agency (151:2003/70403) and the Regional Ethical Review Board in Linköping (M76-05). Amendments were accepted by the Swedish Medical Products Agency 2006-08-31, 2007-05-08, 2007-11-01, and 2007-11-19.

External randomization in variable block sizes was done by Apoteket $\mathrm{AB}$ (Produktion \& Laboratorier, Umeå, Sweden).

External monitoring of all key data and unblinding procedures was done by an independent professional monitoring team (Clinical Research Support, available from: http:// www.orebroll.se/crs).

The recording of adverse events was done according to the Good Clinical Practice standard.

\section{INTERVENTION}

\section{Glutamate Solution}

The glutamate solution was a $500-\mathrm{mL} 0.125 \mathrm{M}$ solution of L-glutamic acid with a pH of 6.0 and $280 \mathrm{mOsmol} / \mathrm{kg}$ containing L-glutamic acid $9.2 \mathrm{~g}, \mathrm{NaCl} 0.8 \mathrm{~g}$, water, and $500 \mathrm{~mL}$ and $\mathrm{NaOH}$ in the amount needed.

The production of glutamate solution and quality control was done by Apoteket AB (Produktion \& Laboratorier).

\section{INCLUSION CRITERIA}

The inclusion criteria were coronary artery bypass surgery for acute coronary syndrome. Patients were eligible for inclusion regardless of whether the procedure was done on pump or off pump or whether the patient had undergone a simultaneous valve procedure.

\section{EXCLUSION CRITERIA}

The exclusion criteria were informed consent not possible because of a critical condition or other reason, the preoperative use of inotropic drugs or mechanical circulatory assistance, preoperative dialysis, redo procedure, an unexpected intraoperative finding or event that increased the magnitude of the procedure to overshadow the originally planned operation, age older than 85 years, body weight greater than $125 \mathrm{~kg}$, and food allergy known to have caused flush, rash, or asthma.

\section{Stopping Criteria}

The safety aspects had priority as stopping criteria. The following stopping criteria were prespecified. The study would be terminated:

If the monitoring or interim analysis revealed an increased rate of stroke or mortality, the study would be terminated before statistical significance was reached.
If unexpected serious adverse events were detected in the glutamate group.

If clinical benefit regarding mortality $(P<.05)$ was reached for glutamate infusion at interim analysis.

If no statistically significant difference was found regarding markers of myocardial injury or renal function in favor of glutamate infusion at interim analysis.

If no absolute difference was found in the primary endpoint in favor of glutamate infusion at the interim analysis.

\section{PRESPECIFIED ENDPOINTS}

\section{Primary Endpoint}

The primary endpoint was a composite of postoperative mortality ( $\leq 30$ days), perioperative myocardial infarction and left ventricular heart failure in association with weaning from cardiopulmonary bypass ${ }^{\mathrm{E} 1}$ or after completion of offpump coronary artery bypass surgery.

Perioperative myocardial infarction. The criteria were based on sustained elevation of troponin- $T$ because of findings demonstrating that early substantial elevation of troponin- $T$ can occur without permanent myocardial injury. ${ }^{\text {E1 }}$ Electrocardiographic Q waves have been found unreliable for diagnosis of perioperative myocardial infarction after cardiac surgery. ${ }^{\text {E2,E3 }}$ Perioperative myocardial infarction was therefore defined by the following criteria: troponin- $\mathrm{T}$ of $2.0 \mu \mathrm{g} / \mathrm{L}$ or greater on the third or fourth postoperative day.

In patients with recent myocardial infarction preoperatively $(<1$ week) or in patients with preoperatively elevated troponin-T levels at least 1 of the following was required:

Troponin-T of $2.0 \mu \mathrm{g} / \mathrm{L}$ or more on the third or fourth postoperative day and creatinine kinase-MB greater than $50 \mu \mathrm{g} / \mathrm{L}$ on the first postoperative morning

Troponin- $\mathrm{T}$ of $2.0 \mu \mathrm{g} / \mathrm{L}$ or more on the third or fourth postoperative day and an increase in troponin- $\mathrm{T}$ greater than $1.5 \mu \mathrm{g} / \mathrm{L}$ compared with the preoperative levels

Left ventricular failure at weaning from cardiopulmonary bypass or after completion of off-pump surgery. Patients were considered to have left ventricular failure at weaning from cardiopulmonary bypass or after completion of off-pump surgery if criteria 1 and 2, 1 and 3, or 1 and 4 were fulfilled.

1. Consensus reached by the Endpoints Committee that left ventricular failure was evident at weaning from cardiopulmonary bypass from the available records and hemodynamic data 
2. Cardiac index of $1.9 \mathrm{~L} / \mathrm{min} / \mathrm{m}^{2}$ body surface area or less with systolic arterial blood pressure (SAP) less than 100 $\mathrm{mm} \mathrm{Hg}$

3. Mixed venous oxygen saturation $\left(\mathrm{SvO}_{2}\right)$ criteria in relation to SAP as listed fulfilled at weaning from cardiopulmonary bypass, 5 minutes after the main dose of protamine sulphate, and on admission to the intensive care unit (ICU) that could not be explained by shivering, anemia, or hypovolemia ${ }^{\mathrm{E} 4-\mathrm{E} 6}: \mathrm{SvO}_{2}$ less than $50 \%$, SAP less than $130 \mathrm{~mm} \mathrm{Hg} ; \mathrm{SvO}_{2}$ less than $55 \%$, SAP less than $110 \mathrm{~mm} \mathrm{Hg} ; \mathrm{SvO}_{2}$ less than $60 \%$, SAP less than $90 \mathrm{~mm} \mathrm{Hg}$; and $\mathrm{SvO}_{2}$ less than $65 \%$, SAP less than 70 $\mathrm{mm} \mathrm{Hg}$

4. Use of intra-aortic balloon pump or the need for at least 1 inotropic agent in the dosages listed in the subsection "Inotrope Dosages" remaining on admission to the ICU

\section{Secondary Endpoints}

The secondary endpoints covered the postoperative hemodynamic state, myocardial ischemia and injury, renal function, and neurologic safety issues.

Hemodynamic state. The postoperative hemodynamic state, use of inotropic drugs and mechanical circulatory support, hemodynamic instability at surgery completion, incidence of severe circulatory failure, need for prolonged ICU stay, cardiac mortality, and late mortality.

Postoperative heart failure was categorized as heart failure evident at weaning from cardiopulmonary bypass or late circulatory failure presenting after apparently uncomplicated weaning. Late circulatory failure was classified as cardiac or noncardiac in origin.

Myocardial ischemia and injury. ST-segment depression of $1 \mathrm{mV}$ or greater or ST-segment elevation of 2 $\mathrm{mV}$ or greater in the operating room on the electrocardiogram before the institution of cardiopulmonary bypass, degree of myocardial injury (creatine kinase-MB on postoperative day 1 , troponin- $\mathrm{T}$ on postoperative day 3 or 4 ).

Postoperative atrial fibrillation. Renal function was determined by plasma creatinine and plasma cystatin $\mathrm{C}$, the need for dialysis, and the incidence of plasma creatinine elevation greater than $50 \%$ compared with the preoperative level.

The neurologic safety issues included stroke less than 24 hours after surgery, stroke during hospitalization, computed tomography scan of the brain in suspected cases, S100 calcium binding protein $\mathrm{B}(\mathrm{S}-100 \mathrm{~B})$ on postoperative day 3 (substudy). ${ }^{\mathrm{E} 7}$

Hemodynamic instability at surgery completion. Patients were considered hemodynamically unstable at surgery completion if the attending anesthesiologist had classified them in the institutional database as hemodynamically unstable despite the use of inotropic drugs or if an intraaortic balloon pump was needed. This classification was performed at the 2 major participating centers, accounting for 788 patients of the 861 included in the trial.

Severe circulatory failure. Patients were considered to have had severe circulatory failure if criteria 1,2, and 3 or 2 and 4 were fulfilled.

1. ICU stay of 48 hours or longer.

2. Consensus reached by Endpoints Committee that heart failure presenting at weaning from cardiopulmonary bypass or later had occurred. This was decision had to be supported by Cardiac Index or $\mathrm{SvO}_{2}$ data identical to those prespecified for the primary endpoint left ventricular failure at weaning from CPB.

3. The use of an intra-aortic balloon pump or the need for at least 1 inotropic agent in dosages listed 24 hours or more after admission to the ICU.

4. Mortality.

\section{Inotrope Dosages}

The dosages of the inotropes required for the preceding criteria were as follows:

Epinephrine $\geq 0.033 \mu \mathrm{g} / \mathrm{kg}$ of body weight per minute.

Milrinone $\geq 0.375 \mu \mathrm{g} / \mathrm{kg}$ of body weight per minute.

Dopamine $\geq 4 \mu \mathrm{g} / \mathrm{kg}$ of body weight per minute.

Dobutamine $\geq 4 \mu \mathrm{g} / \mathrm{kg}$ of body weight per minute.

Levosimendan, regardless of dose plus additional inotropic treatment in dosages as listed.

\section{DATA COLLECTION}

The key study data were prospectively recorded in a case report form. Preoperatively, the patients were classified with regard to the Canadian Cardiovascular Society class and Braunwald class. The occurrence of angina at rest within 48 hours before surgery and the occurrence of STsegment depression of $1 \mathrm{~mm}$ or greater or ST-segment elevation of $2 \mathrm{~mm}$ or greater from admission to the operating room to the onset of cardiopulmonary bypass were recorded. Troponin- $\mathrm{T}$ was sampled immediately before surgery and on the third postoperative day. Creatine kinase-MB was sampled on the first postoperative day. Left ventricular function was assessed by transesophageal echocardiography before the surgical incision and in association with weaning from cardiopulmonary bypass. The hemodynamic variables (ie, mixed venous oxygen saturation, arterial saturation, heart rate, systolic and diastolic arterial pressure, diastolic pulmonary artery pressure, central venous pressure) were recorded at weaning from cardiopulmonary bypass or after termination of the last graft for off-pump surgery, 5 minutes after administration of 
protamine sulphate, and on admission to the ICU. The use of inotropic drugs or mechanical circulatory assistance was recorded. Arterial plasma lactate was measured 5 minutes after administration of protamine sulphate. Plasma cystatin-C and plasma creatinine was sampled on the third postoperative day. The greatest postoperative plasma creatinine level was also registered. Computed tomography was performed in cases with suspected permanent neurologic injury. The basic demographic, intraoperative, and postoperative data were recorded prospectively in an institutional database (Carath) used at all participating centers.

\section{ROUTINES FOR UNBLINDING}

The Swedish Medical Products Agency requested meticulous surveillance and unblinding in cases of computed tomography-verified stroke within 24 hours of surgery, mortality, and suspected unexpected serious adverse reactions. Before unblinding was done, the case was reviewed by the Clinical Endpoints Committee if suspected circulatory problems had occurred. Recording of adverse events was done according to the Good Clinical Practice standard.

\section{CLINICAL MANAGEMENT}

Clinical management was standardized and similar at the 3 participating centers with minor differences concerning the choice of anesthetic drugs. After an overnight fast, the patients received $\beta$-blockers and calcium antagonists orally, but antihypertensive and antidiabetic agents were withheld. The standard premedication consisted of orally administered flunitrazepam 0.5 to $1.0 \mathrm{mg}$ or diazepam 5 to $10 \mathrm{mg}$ and ketobemidone 0.1 to $0.2 \mathrm{mg} / \mathrm{kg}$ body weight or morphine 0.1 to $0.2 \mathrm{mg} / \mathrm{kg}$ body weight. Anesthesia was induced with thiopentone $(2-3 \mathrm{mg} / \mathrm{kg}$ body weight) or propofol ( $2 \mathrm{mg} / \mathrm{kg}$ body weight) supplemented by a bolus dose of fentanyl 3 to $5 \mu \mathrm{g} / \mathrm{kg}$ body weight. Muscle relaxation was achieved with pancuronium 0.1 $\mathrm{mg} / \mathrm{kg}$ body weight or rocuronium $0.6 \mathrm{mg} / \mathrm{kg}$ body weight. Anesthesia was maintained with isoflurane, sevoflurane, or propofol supplemented with intermittent doses of fentanyl.

Standard monitoring was used consisting of a 5-lead echocardiogram, pulse oximetry, continuous arterial blood pressure monitoring using a cannula in the radial artery, central venous pressure, and transesophageal echocardiography. A surgical pulmonary artery catheter was introduced in all patients. ${ }^{\mathrm{E} 4, \mathrm{E} 5}$

Standard surgical techniques were used. A median sternotomy was performed in all patients. The use of cardiopulmonary bypass, a single-clamp technique for aortic crossclamping, the method of myocardial protection, and off-pump surgery are presented in Table 1.
Postoperative sedation was achieved with propofol. The postoperative analgesia regimen consisted of ketobemidone 7 to $15 \mu \mathrm{g} / \mathrm{kg}$ body weight administered intermittent intravenously and acetaminophen $1 \mathrm{~g}$ every sixth hour.

Extubation was performed when the body temperature reached a level greater than $37^{\circ} \mathrm{C}$, the hemodynamic values were stable, including a mixed venous saturation greater than $55 \%$, the oxygen partial pressure was greater than 10 $\mathrm{kPa}$ with fraction of inspired oxygen 0.4 and partial pressure of carbon dioxide was less than $6.5 \mathrm{kPa}$, with a respiratory rate less than 30 per minute and drainage loss less than 100 $\mathrm{mL} / \mathrm{hr}$ and declining.

\section{INVESTIGATORS}

The Sponsor and Principal Investigator was Rolf Svedjeholm, MD, Department of Cardiothoracic Surgery, Linköping University Hospital, Linköping, Sweden.

The remaining investigators were as follows: Erik Håkansson, MD, Jonas Holm, MD, and Farkas Vanky, MD, Department of Cardiothoracic Anesthesiology, Linköping University Hospital, Linköping, Sweden; Mårten Vidlund, MD, Örjan Friberg, MD, and Lena Sunnermalm, MD, Department of Cardiothoracic Surgery and Anesthesiology, Örebro University Hospital, Örebro, Sweden; and Sören Juhl-Andersen, MD, Department of Cardiothoracic Anesthesiology, Blekinge Hospital, Karlskrona, Sweden (deceased); Jan Olov Borg, MD, Department of Cardiothoracic Surgery, Blekinge Hospital, Karlskrona, Sweden; Rajiv Sharma, MD, Department of Cardiothoracic Anesthesiology, Blekinge Hospital, Karlskrona, Sweden.

\section{Clinical Endpoints Committee}

The Clinical Endpoints Committee consisted of consultants in cardiothoracic surgery and cardiothoracic anesthesiology from each of the participating centers. The members of the committee were unaware of the treatment assignment and prespecified criteria reported in the Appendix were used to reach a consensus decision.

All patients with suspected postoperative heart failure based on the $\mathrm{SvO}_{2}$ and other hemodynamic data, the use of inotropic drugs or mechanical circulatory support, an extended ICU stay, and circulatory problems reported by the anesthesiologists or surgeons in the clinical database were reviewed. The committee decided whether the circulatory problems that met the prespecified criteria had occurred, whether these circulatory problems were severe, whether they were cardiac in origin, whether they were evident at weaning from cardiopulmonary bypass or presented later in the postoperative course. The committee also decided whether events leading to death were cardiac in origin. 


\section{E-References}

E1. Dahlin LG, Kagedal B, Nylander E, Olin C, Rutberg H, Svedjeholm R. Unspecific elevation of plasma troponin-T and CK-MB after coronary surgery. Scand Cardiovasc J. 2003;37:283-7.

E2. Hodakowski GT, Craver JM, Jones EL, King SB III, Guyton RA. Clinical significance of perioperative Q-wave myocardial infarction: the Emory Angioplasty Versus Surgery Trial. J Thorac Cardiovasc Surg. 1996;112:1447-54.

E3. Svedjeholm R, Dahlin LG, Lundberg C, Szabo Z, Kagedal B, Nylander E, et al. Are electrocardiographic Q-wave criteria reliable for diagnosis of perioperative myocardial infarction after coronary surgery? Eur J Cardiothorac Surg. 1998;13:655-61.

E4. Holm J, Hakanson E, Vanky F, Svedjeholm R. Mixed venous oxygen saturation predicts short- and long-term outcome after coronary artery bypass

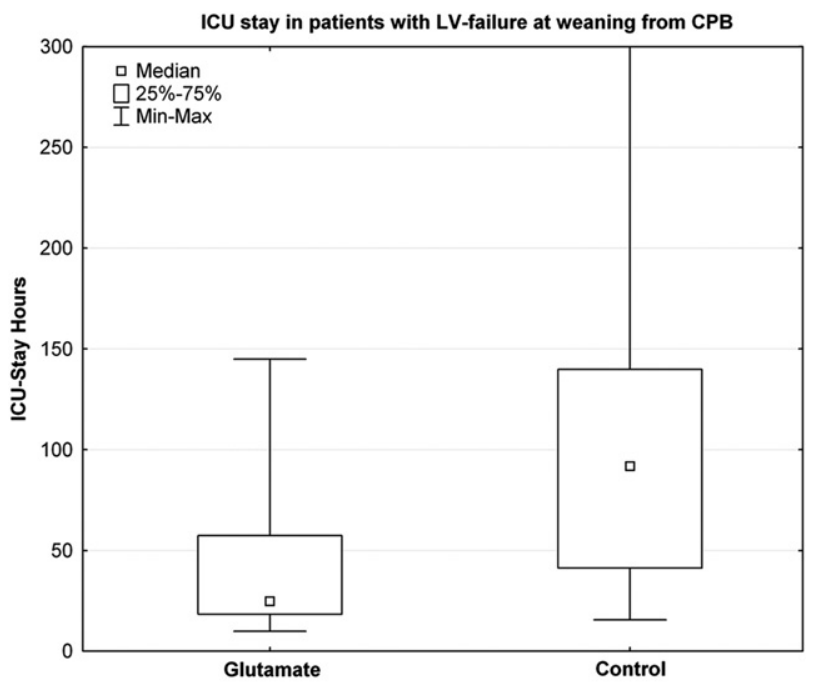

A

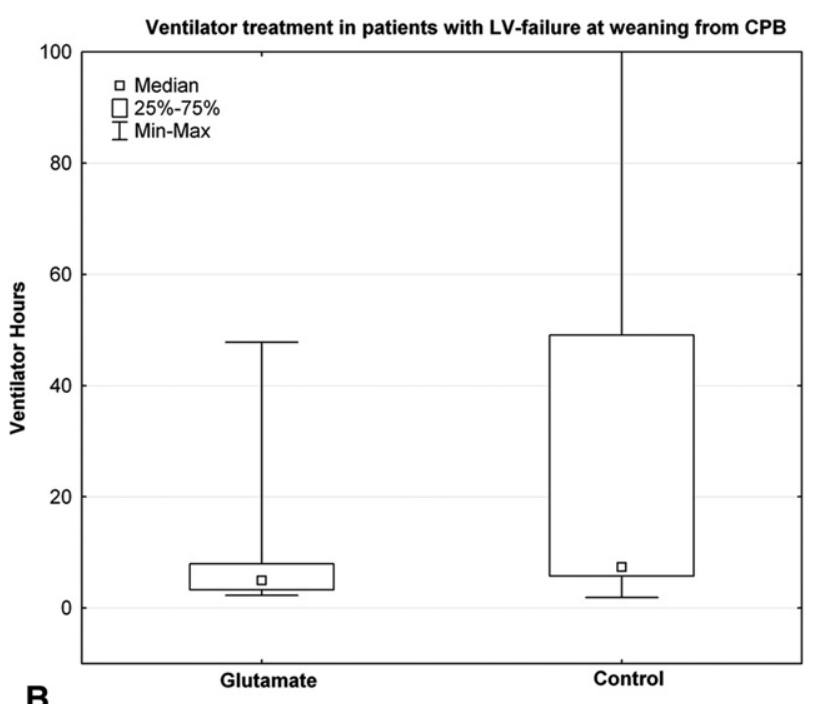

FIGURE E1. Duration of (A) intensive care unit (ICU) stay and (B) ventilator treatment in patients with left ventricular failure at weaning from cardiopulmonary bypass in the glutamate group $(\mathrm{n}=20)$ or control group (n = 18). $L V$, Left ventricular; $C P B$, cardiopulmonary bypass. grafting surgery: a retrospective cohort analysis. Br J Anaesth. 2011;107: 344-50.

E5. Svedjeholm R, Hakanson E, Szabo Z. Routine $\mathrm{SvO}_{2}$ measurement after CABG surgery with a surgically introduced pulmonary artery catheter. Eur J Cardiothorac Surg. 1999;16:450-7.

E6. Svedjeholm R, Vidlund M, Vanhanen I, Hakanson E. A metabolic protective strategy could improve long-term survival in patients with LV-dysfunction undergoing CABG. Scand Cardiovasc J. 2010;44:45-58.

E7. Vidlund M, Holm J, Hakanson E, Friberg O, Sunnermalm L, Vanky F, et al. The S-100B substudy of the GLUTAMICS trial: glutamate infusion not associated with sustained elevation of plasma S-100B after coronary surgery. Clin Nutr. 2009;21:358-64.
TABLE E1. Multivariate analysis of risk factors for severe circulatory failure in patients with CCS class IV angina undergoing isolated CABG

\begin{tabular}{lclc}
\hline \multicolumn{1}{c}{ Variable } & Adjusted OR & \multicolumn{9}{c}{$\mathbf{9 5} \% \mathbf{C I}$} & $\begin{array}{c}\boldsymbol{P} \\
\text { value }\end{array}$ \\
\hline Preoperative troponin-T level* & 2.2 & $1.3-3.7$ & .004 \\
Extracardiac vascular disease & 6.5 & $1.8-23.6$ & .005 \\
Severe systolic LV dysfunction & 7.3 & $1.6-34.6$ & .01 \\
Emergency procedure & 5.1 & $1.4-18.9$ & .01 \\
Intravenous glutamate infusion & 0.2 & $0.04-0.72$ & .02 \\
ST-segment depression $\geq 1 \mathrm{mV}$ & 3.8 & $1.0-14.4$ & .05 \\
\hline
\end{tabular}

Variables were tested 1 at a time and those considered clinically relevant or with $P<.25$ were tested with forward stepwise multiple logistic regression analysis. Hosmer-Lemeshow goodness-of-fit statistics were calculated for the final model. Variables: age, gender, weight, body mass index, diabetes, hypertension, chronic obstructive pulmonary disease, extracardiac arterial disease, cerebrovascular disease, previous vascular surgery, preoperative hemoglobin, preoperative plasma creatinine, preoperative troponin- $\mathrm{T}$, triple-vessel disease, left main disease, previous myocardial infarction, recent preoperative myocardial infarction, preoperative left ventricular dysfunction, preoperative atrial fibrillation, Braunwald class, Canadian Cardiovascular Society class, angina at rest $<48$ hours from surgery, preoperative treatment with intravenous nitrates, emergency procedure, ST-segment depression $\geq 1 \mathrm{mV}$ on the electrocardiogram in the operating room before institution of cardiopulmonary bypass, the use of crystalloid/blood cardioplegia, number of bypassed vessels, aortic crossclamp time, and intravenous glutamate infusion. The influence of the additive European System for Cardiac Operative Risk Evaluation and postoperative bleeding or tamponade on the role of intravenous glutamate in the final model was also tested. Hosmer-Lemeshow goodness-of-fit test chi square (df 5) $=3.51, P=.62$. CI, Confidence interval; $L V$, left ventricular; $O R$, odds ratio; $C C S$, Canadian Cardiovascular Society; $C A B G$, coronary artery bypass grafting. *Per unit change. 
TABLE E2. Incidence of severe postoperative circulatory failure

\begin{tabular}{|c|c|c|c|c|c|c|}
\hline & Control/glutamate & Control & Glutamate & $\mathbf{R R}$ & $95 \% \mathrm{CI}$ & $P$ value \\
\hline Isolated CABG & $413 / 411$ & $16(3.9 \%)$ & $6(1.5 \%)$ & 0.38 & $0.15-0.95$ & .04 \\
\hline NSTEMI only & $68 / 59$ & $1(1.5 \%)$ & $1(1.7 \%)$ & 1.15 & $0.07-18$ & .92 \\
\hline Diabetes & $108 / 98$ & $4(3.7 \%)$ & $4(4.1 \%)$ & 1.10 & $0.28-4.3$ & .89 \\
\hline No diabetes & $305 / 313$ & $12(3.9 \%)$ & $2(0.6 \%)$ & 0.16 & $0.04-0.72$ & .02 \\
\hline CCS class IV & $233 / 225$ & $16(6.9 \%)$ & $3(1.3 \%)$ & 0.19 & $0.06-0.66$ & .008 \\
\hline Left main stenosis $>50 \%$ & $141 / 174$ & $10(7.1 \%)$ & $1(0.6 \%)$ & 0.08 & $0.01-0.63$ & .02 \\
\hline Female gender & $77 / 70$ & $7(8.5 \%)$ & $2(2.7 \%)$ & 0.31 & $0.26-1.2$ & .14 \\
\hline euroSCORE $\geq 8$ & $63 / 83$ & $9(14.3 \%)$ & $4(4.8 \%)$ & 0.34 & $0.11-1.05$ & .06 \\
\hline Severe LV dysfunction & $20 / 14$ & $5(25 \%)$ & $1(7.1 \%)$ & 0.29 & $0.04-2.2$ & .23 \\
\hline Emergency* & $13 / 14$ & $4(31 \%)$ & $1(7.1 \%)$ & 0.23 & $0.03-1.6$ & .16 \\
\hline LV failure at weaning & $14 / 18$ & $8(57 \%)$ & $2(11 \%)$ & 0.19 & $0.05-0.78$ & .02 \\
\hline
\end{tabular}

Data presented as relative risk $\pm 95 \%$ confidence interval of developing severe postoperative circulatory failure associated with glutamate treatment. Results were approximate, given the small number of events (MedCalc Software, Mariakerke, Belgium). CABG, Coronary artery bypass grafting; CCS, Canadian Cardiovascular Society; $C I$, confidence interval; euroSCORE, European System for Cardiac Operative Risk Evaluation; NSTEMI, non-ST-segment elevation myocardial infarction; $L V$, left ventricular; $R R$, relative risk.

*Emergency according to euroSCORE definition. 
TABLE E3. Preoperative and intraoperative data for patients surgically treated for acute coronary syndrome during the study period but not included in the GLUTAMICS trial $(n=780 *)$

\begin{tabular}{|c|c|}
\hline Variable & Value \\
\hline Age (y) & $68 \pm 9$ \\
\hline \multicolumn{2}{|l|}{ Gender } \\
\hline Female & $26.3 \%$ \\
\hline Male & $73.7 \%$ \\
\hline Length (cm) & $172 \pm 9$ \\
\hline Weight $(\mathrm{kg})$ & $81 \pm 15$ \\
\hline BMI $\left(\mathrm{kg} / \mathrm{m}^{2}\right)$ & $27 \pm 4$ \\
\hline euroSCORE $\dagger$ & $6.1 \pm 3.9$ \\
\hline Blood hemoglobin $(\mathrm{g} / \mathrm{L})$ & $134 \pm 17$ \\
\hline Plasma creatinine $(\mu \mathrm{mol} / \mathrm{L})$ & $100 \pm 44$ \\
\hline Active smokers & $17.4 \%$ \\
\hline COPD & $7.1 \%$ \\
\hline Hypertension & $61.6 \%$ \\
\hline Diabetes & $28.1 \%$ \\
\hline Cerebrovascular disease & $8.6 \%$ \\
\hline Extracardiac arterial disease & $11.4 \%$ \\
\hline Previous vascular surgery & $4.6 \%$ \\
\hline Carotid artery stenosis & $3.2 \%$ \\
\hline \multicolumn{2}{|l|}{ Multivessel disease } \\
\hline 2-Vessel disease & $18.4 \%$ \\
\hline 3-Vessel disease & $75.7 \%$ \\
\hline Left main stem stenosis & $44.1 \%$ \\
\hline \multicolumn{2}{|l|}{ Recent myocardial infarction } \\
\hline $0-24 \mathrm{~h}$ & $5.8 \%$ \\
\hline $1-7 d$ & $21.4 \%$ \\
\hline $8-21 \mathrm{~d}$ & $28.6 \%$ \\
\hline Intravenous nitroglycerine preoperatively & $11.5 \%$ \\
\hline \multicolumn{2}{|l|}{ LV dysfunction } \\
\hline Moderate & $15.2 \%$ \\
\hline Severe & $10.7 \%$ \\
\hline Emergency procedure & $11.5 \%$ \\
\hline Operation other than isolated CABG & $12.8 \%$ \\
\hline OPCAB & $5.1 \%$ \\
\hline CPB time (min) & $95 \pm 47$ \\
\hline Aortic crossclamp time (min) & $58 \pm 29$ \\
\hline Single clamp & $20.7 \%$ \\
\hline Bypasses (n) & $3.5 \pm 1.2$ \\
\hline
\end{tabular}

Data presented as mean \pm standard deviation or percentages. $B M I$, Body mass index; $C P B$, cardiopulmonary bypass; euroSCORE, European System for Cardiac Operative Risk Evaluation; LITA, left internal thoracic artery; $L V$, left ventricular (dysfunction according to echocardiography); OPCAB, off-pump coronary artery bypass; GLUTA$M I C S$, GLUTAmate for Metabolic Intervention in Coronary Surgery; $C O P D$, chronic obstructive pulmonary disease; $C A B G$, coronary artery bypass grafting. *Complete data available from 2 of participating centers $(n=780)$. †Additive euroSCORE.
TABLE E4. Outcome data for patients undergoing surgery for acute coronary syndrome during study period but not included in GLUTAMICS trial $(\mathbf{n}=\mathbf{7 8 0} *)$

\begin{tabular}{lc}
\hline \multicolumn{1}{c}{ Variable } & Value \\
\hline 30-d Mortality $\dagger$ & $4.0 \%$ \\
Inotropes in OR > 30 min & $34.2 \%$ \\
Hemodynamic state at surgery completion & \\
$\quad$ Stable without inotropes & $65.4 \%$ \\
Stable with inotropes & $29.7 \%$ \\
$\quad$ Unstable with inotropes/IABP & $4.3 \%$ \\
Creatine kinase-MB ( $\mu \mathrm{g} / \mathrm{L}$ ) day 1 postoperatively & \\
$\quad$ Median & 15 \\
$\quad$ Interquartile range & $10-27$ \\
Troponin-T ( $\mu \mathrm{g} / \mathrm{L}$ ) day 3-4 postoperatively & \\
$\quad$ Median & 0.4 \\
$\quad$ Interquartile range & $0.1-1.4$ \\
Peak plasma creatinine ( $\mu$ mol/L) & $121 \pm 86$ \\
Dialysis postoperatively & $2.2 \%$ \\
ICU duration (h) & \\
$\quad$ Median & 22 \\
$\quad$ Interquartile range & $18-37$ \\
Ventilator duration (h) & \\
$\quad$ Median & \\
Interquartile range & 5.3 \\
Postoperative atrial fibrillation & $3.5-8.8$ \\
Reoperation for bleeding/tamponade & $32.8 \%$ \\
Reoperation sternal infection/dehiscense & $5.8 \%$ \\
Stroke during hospital stay & $1.7 \%$ \\
\hline Da & $2.3 \%$ \\
\hline
\end{tabular}

Data presented as median and interquartile range, mean \pm standard deviation, or numbers with percentages in parentheses. GLUTAMICS, GLUTAmate for Metabolic Intervention in Coronary Surgery; $I A B P$, intra-aortic balloon pump; $I C U$, intensive care unit; $O R$, operating room. *Complete data available from 2 of participating centers $(\mathrm{n}=780)$. $\dagger$ Data from all 3 participating centers $(\mathrm{n}=1222)$. 
TABLE E5. Adverse events in study population

\begin{tabular}{lccc}
\hline \multicolumn{1}{c}{ Variable } & $\begin{array}{c}\text { Placebo } \\
(\mathbf{n}=\mathbf{4 3 3})\end{array}$ & $\begin{array}{c}\text { Glutamate } \\
(\mathbf{n}=\mathbf{4 2 8})\end{array}$ & $\begin{array}{c}\boldsymbol{P} \\
\text { value }\end{array}$ \\
\hline All adverse events & 364 & 381 & \\
Patients with $\geq 1$ serious adverse event & $59(13.6)$ & $54(12.6)$ & .69 \\
Serious adverse events & 82 & 76 & \\
Circulatory & $21(4.8)$ & $12(2.8)$ & .15 \\
Perioperative myocardial infarction & $6(1.4)$ & $11(2.6)$ & .23 \\
Reoperation for bleeding & $21(4.8)$ & $22(5.1)$ & .88 \\
Respiratory & $6(1.4)$ & $8(1.9)$ & .60 \\
Gastrointestinal & $2(0.5)$ & $1(0.2)$ & 1.0 \\
Renal/urinary tract & $9(2.1)$ & $8(1.9)$ & 1.0 \\
Central nervous system & $7(1.6)$ & $9(2.1)$ & .62 \\
Infections & $8(1.8)$ & $4(0.9)$ & .38 \\
Other & $2(0.5)$ & $1(0.2)$ & 1.0 \\
Nonserious adverse events* & 282 & 305 & \\
Circulatory $\dagger$ & $53(13.4)$ & $57(14.5)$ & .68 \\
Respiratory & $45(11.4)$ & $39(9.9)$ & .56 \\
Gastrointestinal & $6(1.4)$ & $5(1.2)$ & 1.0 \\
Postoperative nausea and vomiting & $114(27.9)$ & $139(34.0)$ & .06 \\
Renal/urinary tract & $18(4.2)$ & $22(5.1)$ & .52 \\
Central nervous system & $10(2.5 \%)$ & $5(1.3 \%)$ & .30 \\
Infections & $27(6.8 \%)$ & $33(8.4 \%)$ & .42 \\
Skin & $7(1.8 \%)$ & $3(0.8 \%)$ & .34 \\
Other & $2(0.5 \%)$ & $2(0.5 \%)$ & 1.0 \\
\hline Da preser & & &
\end{tabular}

Data presented as numbers with percentages in parentheses. *Complete data for nonserious adverse events only available from 2 largest participating centers $(\mathrm{n}=788)$.

$\dagger$ Postoperative atrial fibrillation not included because it was presented in Table 2. 